University of Nebraska - Lincoln

DigitalCommons@University of Nebraska - Lincoln

\title{
Experimental determination of probabilistic edge-delamination strength of a graphite-fiber/epoxy composite
}

\author{
Xiangfa Wu \\ Department of Engineering Mechanics, University of Nebraska-Lincoln, xfwu@unlserve.unl.edu
}

Yuris A. Dzenis

Department of Engineering Mechanics, University of Nebraska-Lincoln, ydzenis@unl.edu

Follow this and additional works at: https://digitalcommons.unl.edu/engineeringmechanicsfacpub

Part of the Mechanical Engineering Commons

Wu, Xiangfa and Dzenis, Yuris A., "Experimental determination of probabilistic edge-delamination strength of a graphite-fiber/epoxy composite" (2005). Faculty Publications from the Department of Engineering Mechanics. 24.

https://digitalcommons.unl.edu/engineeringmechanicsfacpub/24

This Article is brought to you for free and open access by the Mechanical \& Materials Engineering, Department of at DigitalCommons@University of Nebraska - Lincoln. It has been accepted for inclusion in Faculty Publications from the Department of Engineering Mechanics by an authorized administrator of DigitalCommons@University of Nebraska - Lincoln. 
Published in Composite Structures 70:1 (August 2005), pp. 100-108; doi 10.1016/j.compstruct.2004.08.016

Copyright (C) 2004 Elsevier Ltd. Used by permission. http://www.elsevier.com/wps/product/cws_home/405928

Published online September 13, 2004.

\title{
Experimental determination of probabilistic edge-delamination strength of a graphite-fiber/epoxy composite
}

\author{
Xiang-Fa Wu and Yuris A. Dzenis \\ Department of Engineering Mechanics, Center for Materials Research and Analysis, \\ University of Nebraska-Lincoln, Lincoln, NE 68588-0526, USA \\ Corresponding author - X.-F. Wu, email xfwu@unlserve.unl.edu ; fax 402 472-8292
}

\begin{abstract}
Probabilistic edge-delamination strength of a thermosetting polymer composite was studied experimentally in this work. During the procedure, by means of edge-delamination tensile test, the graphite-fiber/epoxy laminate made of unidirectional Toray P7051S-20Q-1000 prepregs with an optimized lay-up of $\left[12_{2} /-12_{2} / 0_{2}\right]_{S}$ was used for examining its probabilistic distributions of the edge-delamination onset stress and the ultimate tensile strength. Acoustic emission (AE) equipment and optical microscope were utilized to capture the edge-delamination initiation and characterize the failure modes during delaminating. Fractographical analysis based on scanning electron microscope (SEM) was conducted for the characterization of the microscopic failure mechanisms of the composite laminate during edge delaminating. Probabilistic models were introduced for data reduction. Test results show that the edge-delamination onset stress and the ultimate tensile strength of the laminate tested satisfy two two-parameter Weibull distributions very well. AE signals show the main failure mode during edge delaminating is interlaminar shear failure, corresponding to that predicted by numerical simulation and confirmed by SEM fractographical results in this study.
\end{abstract}

Keywords: graphite-fiber/epoxy composite, edge delamination, free-edge stresses, edge-delamination onset stress, acoustic emission (AE), probabilistic strength, Weibull distribution, SEM fractographical analysis

\section{Introduction}

It is well understood that near free edges of composite laminates, interlaminar stresses arise due to a mismatch of elastic properties between two neighboring laminas. Localized high interlaminar stresses may lead to delamination failure near these free edges. Edge delamination has attracted significant attention over three decades both in free-edge stress approaches and edge-delamination suppression techniques. Historically, Pipes and Pagano [1-2] pioneered the free-edge stress analysis of angle-ply composite laminates by means of finite difference method. Their numerical approaches indicated that there exists high interlaminar stress concentration near free edges, which was further confirmed by experimental observations. After Pipes and Pagano's works [1-2], a number of theoretical investigations based largely on finite element method and semi-analytic stress potentials have been contributed to free-edge stress analyses in the last two decades [3-21]. So far, several efficient numerical algorithms have been developed for predicting interlaminar stress distribution near free-edges of composite laminates, which are valuable for laminate designs and edge strength evaluations. Correspondingly, a few passive and active free-edge delaminationsuppression concepts have been proposed to improve the edge-delamination resistance of various composite laminates, e.g. change of stacking sequence, edge reinforcement (edge cap, edge stitching, and edge interleaved adhesive layers etc.), and edge modification (ply termination, edge notching, and edge tapering etc.) etc. [22]. Recently, researchers have begun working on im- 
provement of the edge-delamination resistance of composite laminates based on nanotechnologies [23]. A detailed literature review on free-edge stress approaches, free-edge delamination-suppression methods and their recent developments can be found in $\mathrm{Wu}$ (2003) [23]. It is obvious that these suppression methods enhance the free-edge delamination resistance by either modifying the localized stress field near free edges or improving the interfacial fracture toughness between two neighboring laminas of composite laminates. However, in attempt to achieve the goal of reliable analysis of composite laminates and successful choice of free-edge delamination-suppression methods, a deep understanding of the probabilistic distribution of edge-delamination onset stress of composite laminates and the characterization of microscopic mechanisms of edge delamination is of critical importance.

Nevertheless, according to the authors' knowledge, no experimental data and theoretical models are yet available in literature concerning the probabilistic distribution of edge-delamination onset stress of composite laminates. Thus, in this experimental study we tried to determine the probabilistic distributions of edge-delamination onset stress and ultimate tensile strength of an angle-ply graphite-fiber/epoxy laminate. The edgedelamination failure mechanisms of the laminate tested were further verified. During this investigation, we first designed an angle-ply composite laminate with an optimized lay-up by a numerical scheme [23] in order to induce maximum interlaminar shear between two targeted neighboring laminas of the composite laminate under constant tensile strain. The numerical scheme used in this study was based on the principle of complementary strain energy and modified Yin's piecewise stress potentials [12-13]. Edge-delamination test was performed on a regular material-testing machine installed with acoustic emission (AE) equipment and an optical microscope, which were used to capture the edge-delamination onset and the acoustic signals during edge delaminating. Furthermore, a detailed fractographical analysis of the specimens after edge delaminating was performed using a scanning electron microscope (SEM). Probabilistic models of Weibull distribution are introduced for data reduction of the edge-delamination onset stress and the ultimate tensile strength of the laminate tested. AE signals and SEM fractographical results are further utilized for the characterization of the failure modes and the mi- croscopic failure mechanisms of the specimens during edge delaminating.

\section{Laminate design}

The thermosetting polymer composite laminate used for this study was made of Toray P7051S-20Q-1000 prepregs supplied by Toray Composites America. The unidirectional prepreg was reinforced by T700S graphite fibers. Mechanical properties of the unidirectional laminate were provided by the manufacturer (Toray America, Inc.) as shown in Table 1.

Elastic moduli of the unidirectional laminate in its material coordinate system can be expressed in terms of $E_{1}=135 \mathrm{GPa}, E_{2}=E_{2}=8.5 \mathrm{GPa}, G_{12}=G_{13}=4.7 \mathrm{GPa}$, $v_{12}=v_{13}=0.34$.

The laminate coordinate system used for free-edge stress prediction is shown in Figure 1. In attempt to induce maximum out-of-plane shear near free-edges of the laminate under axial tension, we chose the laminate lay-up angle corresponding to the peak out-of-plane shear near the free-edge of a symmetric angle-ply laminate with a $[\theta /-\theta]_{S}$ lay-up under constant axial tension $\left(\varepsilon_{x}\right)$ as shown in Figure 2. This lay-up angle is close to the off-axis angle with the peak coefficient of mutual influence of the second kind, $\eta_{i j, i}$ which characterizes the shearing in the ij-plane caused by normal stress in the $i$-direction $[\cdots$

$$
\eta_{i j, i}=\frac{\gamma_{i j}}{\varepsilon_{i}}
$$

for $\sigma_{i}=\sigma$ and all other stresses are zero. Variation of the shear-extension coupling coefficients with off-axis angle is shown in Figure 3. It is found that the peak values occur at $\theta \approx 12^{\circ}$ and $78^{\circ}$, respectively.

It should be mentioned that by assuming the loading condition of constant axial traction $\left(\sigma_{x}\right)$, the out-ofplane shear in the above laminate with a $[\theta /-\theta]_{S}$ lay-up will vary with $\theta$ as shown in Figure 4, where the peak out-of-shear values occurred at $\theta \approx 45^{\circ}$ and $\theta \approx 78^{\circ}$, respectively. However, in realistic polymer composite systems, angle plies in laminates are generally under constrained deformations, thus the stress profiles under fixed strains are more convenient for lay-up design of real laminates. Thus, in this study we chose the composite laminate of a $\left[12_{2} /-12_{2} / 0_{2}\right]_{S}$ lay-up to induce maxi-

Table 1. Mechanical properties of unidirectional composite (\#2500-250F curable epoxy)

\begin{tabular}{|c|c|c|c|c|c|c|c|c|}
\hline \multirow[t]{2}{*}{ Series } & \multirow[t]{2}{*}{ Fiber Type } & \multicolumn{3}{|c|}{ Transverse $\left(90^{\circ}\right)$ tensile } & \multicolumn{3}{|c|}{ Longitudinal $\left(0^{\circ}\right)$ tensile } & \multirow[b]{2}{*}{$\begin{array}{l}\text { Composite } \\
\text { density }\left(V_{\mathrm{f}} 60 \%\right)\left(\mathrm{g} / \mathrm{cm}^{3}\right)\end{array}$} \\
\hline & & $\begin{array}{l}\text { Strength } \\
\text { (MPa) }\end{array}$ & $\begin{array}{l}\text { Modulus } \\
\text { (GPa) }\end{array}$ & $\begin{array}{l}\text { Ultimate } \\
\text { strain (\%) }\end{array}$ & $\begin{array}{l}\text { Strength } \\
(\mathrm{MPa})\end{array}$ & $\begin{array}{l}\text { Modulus } \\
\text { (GPa) }\end{array}$ & $\begin{array}{l}\text { Ultimate } \\
\text { strain (\%) }\end{array}$ & \\
\hline $\mathrm{T} \& \mathrm{H}$ & T700S & 79 & 8.5 & 0.9 & 2.55 & 135 & 1.7 & 1.57 \\
\hline
\end{tabular}




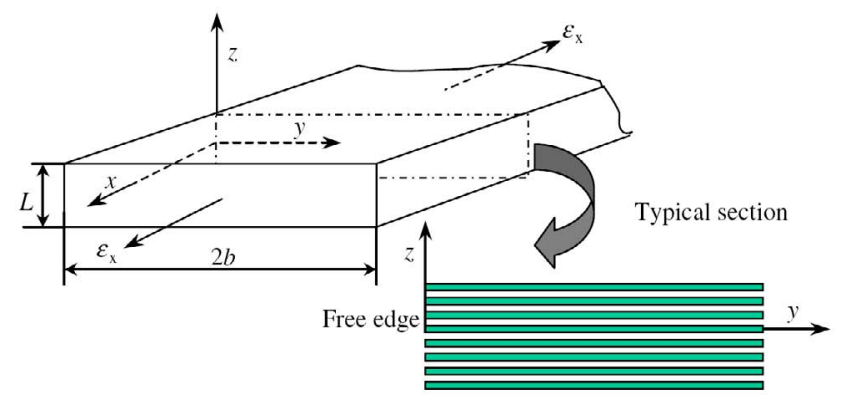

Figure 1. Geometry and coordinate system for laminate freeedge problem.

mum out-of-plane shear near free-edges along the $12^{\circ}$ /$12^{\circ}$ interfaces under constant axial tensile strain $\left(\varepsilon_{x}\right)$. The numerical results plotted in Figure 2 and Figure 4 were obtained using a robust numerical scheme [23] based on the principle of complementary strain energy and modified Yin's piecewise stress potentials [12-13].

Free-edge stresses of the laminate made of Toray P7051S-20Q-1000 prepregs with a $\left[12_{2} /-12_{2} / 0_{2}\right]_{S}$ lay-up were approached using the above numerical scheme. The coordinate system used in the numerical procedure is shown in Figure 1, where the $x$-axis is fixed along the specimen length direction, the $y$-axis along the width direction, and the $z$-axis is perpendicular to the laminate mid-plane. The free-edge stress distribution under constant tensile strain $\varepsilon_{1}=0.02$ is shown in Figure 5. It is clear that high stress concentration exists near free-edges along the $12^{\circ} /-12^{\circ}$ interfaces of the laminate, which are the targeted interfaces where edge-delamination may first occur during the test.

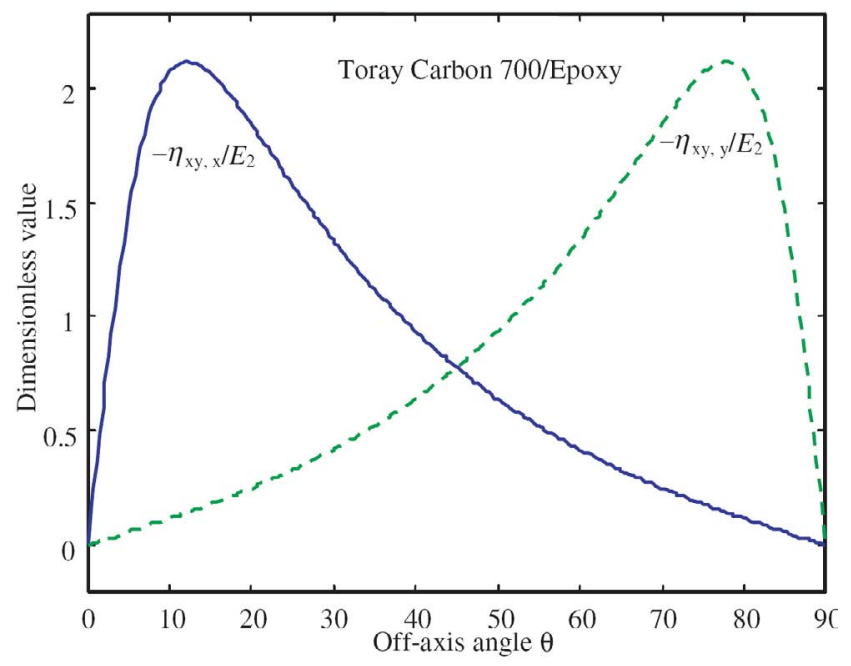

Figure 3. Variation of shear-extension coupling coefficients with off-axis angle.

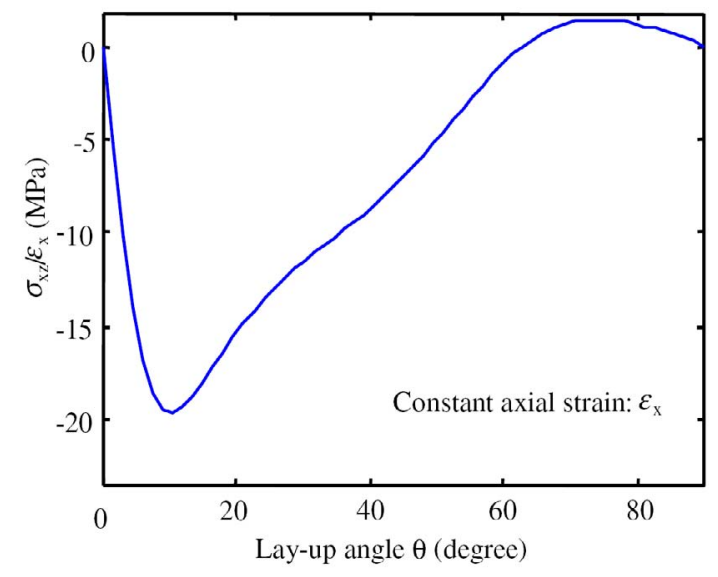

Figure 2. Variation of out-of-plane shear $\sigma_{x z}$ along $\theta /-\theta$ interface in a $[\theta /-\theta]_{S}$ laminate.

\section{Experimental}

\subsection{Specimen manufacturing and preparation}

In this experimental investigation, two laminated panels with a $\left[12_{2} /-12_{2} / 0_{2}\right]_{S}$ lay-up were assembled following hand lay-up procedure and cured in a two-chamber press-clave under controlled temperature, pressure, and vacuum environments according to the manufacturer-recommended curing cycle (Figure 6 and Figure 7). The laminate panels after curing were tabbed using strips cut from a commercial glass-fiber reinforced woven composite panel. The tabbing prevented premature failure of composites near the sample ends and reduced acoustic noises from grips. Rectangular composite specimens were machined from tabbed panels using a highspeed diamond saw with a water-cooling system. The specimen dimensions were $140 \mathrm{~mm}$ in length, $20 \mathrm{~mm}$ in width, and $2.1 \mathrm{~mm}$ in thickness. All free-edge surfaces were carefully polished using fine sandpaper to avoid premature edge delaminating due to free-edge damages caused during specimen machining and handling.

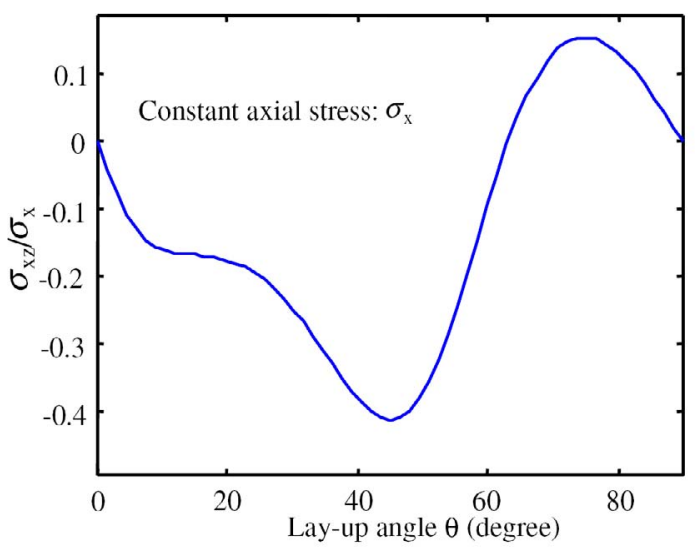

Figure 4. Variation of out-of-plane stress $\sigma_{x z}$ with lay-up angle $\theta$ in $[\theta /-\theta]_{S}$ laminate. 

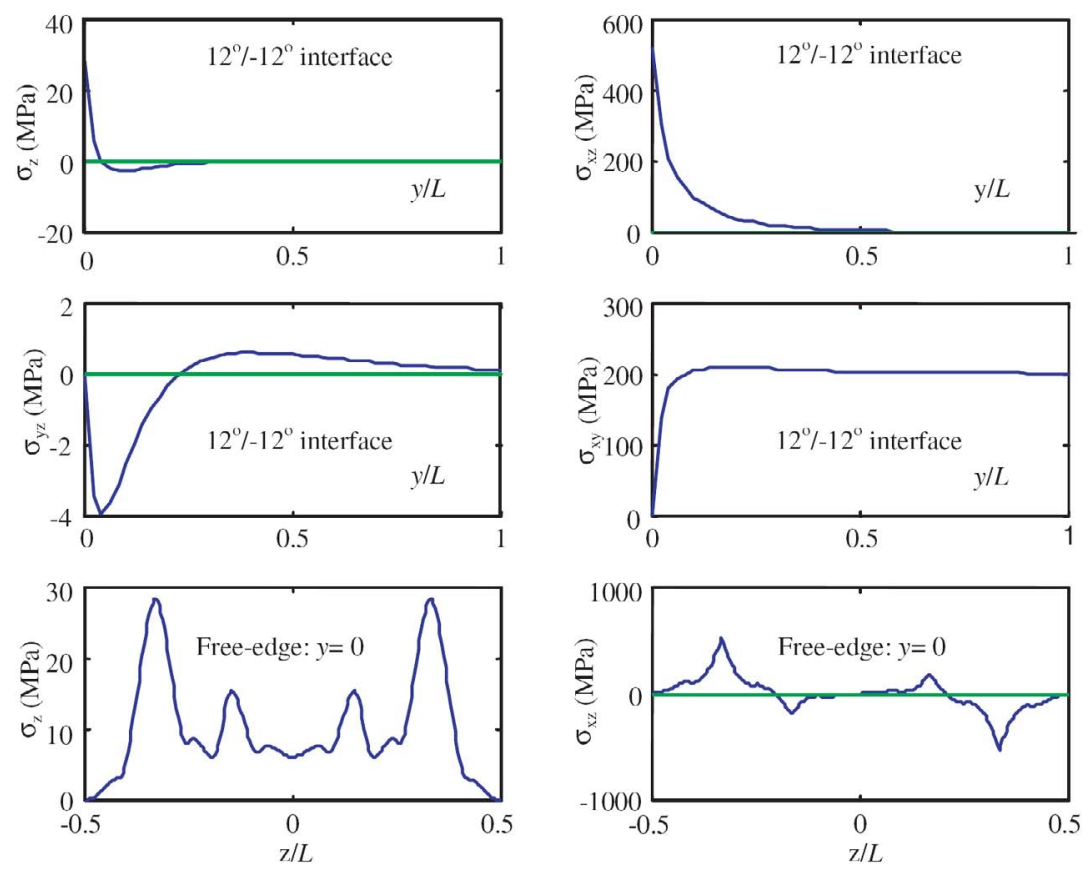

Figure 5. Free-edge stresses in $\left[12_{2} /-12_{2} / 0_{2}\right]_{s}$ laminate ( $L$ : laminate thickness; tensile strain $\varepsilon_{x}=0.02$ ).

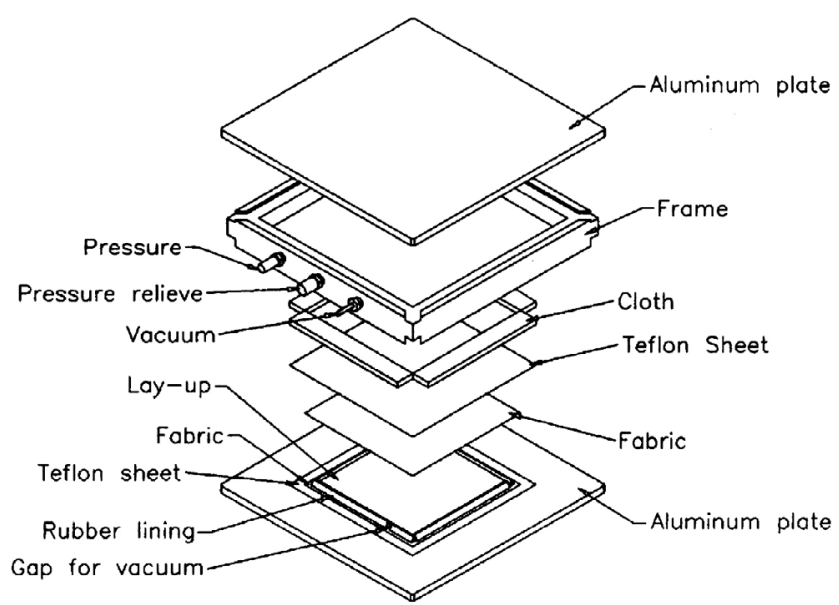

Figure 6. Manufacturing assembly.

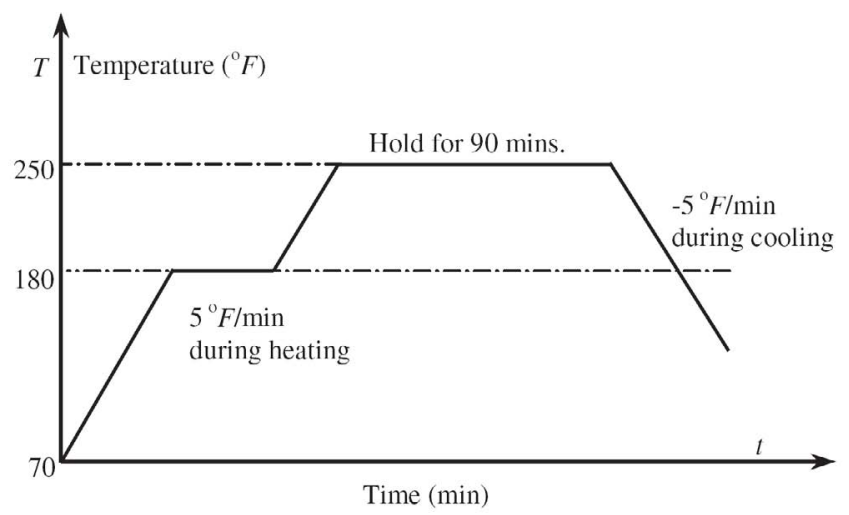

Figure 7. Curing cycle of Toray P7051S-20Q-1000 prepregs.

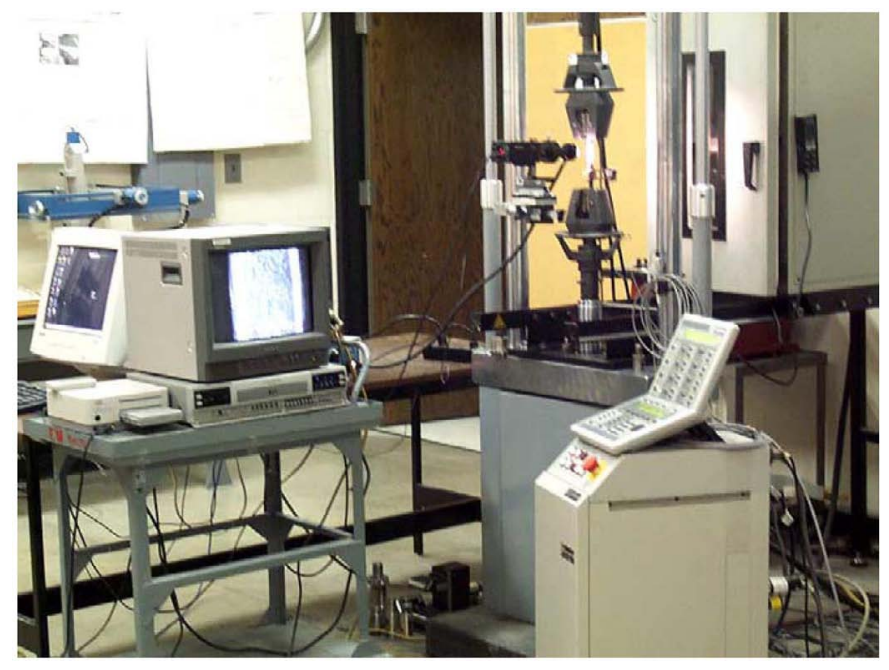

Figure 8. Edge-delamination tensile testing setup.

\subsection{Edge-delamination test procedure and results}

Edge-delamination tensile tests were performed on a servohydraulic MTS testing machine digitally controlled with an Instron test control and data acquisition system (Figure 8). All tests were conducted under stroke control with Instron 8500 software. Specimens were clamped with serrated wedge action grips. Special care was exercised while installing specimens in the grips to ensure alignment. Additional alignment was provided using a Satec spherical alignment coupling. The displacement rate used during testing was $0.5 \mathrm{~mm} / \mathrm{min}$. 
A two-channel AMS3 AE system by Vallen Systeme, $\mathrm{GmbH}$ (Germany), was used for recording acoustic signals during edge-delamination initiation. In this test, only one AE channel was used (Figure 9). AE events were acquired by the sensor as analog signals, and then they were preamplified and converted into digital signals by an A/D converter. The AE signal parameters were then extracted by the system, augmented with the time of arrival and external parameters (load and strain), and recorded in a parametric AE file [24-25]. During the procedure, a $34.5 \mathrm{~dB}$ system gain and a $25.0 \mathrm{~dB}$ threshold were used, and the sampling rate of the AMS3 AE system was $5.0 \mathrm{MHz}$. In parallel, a digital video microscope was installed for capturing the edge delamination initiation.

Typical stress-strain curve under tensile loading is shown in Figure 10. It can be seen that there exist stress drops corresponding to the stiffness decreases at the edge-delamination onset and crack growth afterwards. Figure 11 shows that the edge-delamination grew along $12^{\circ} /-12^{\circ}$ interfaces, corresponding to that predicted by Figure 5.

Typical transient AE signals and their corresponding frequency spectra are shown in Figure 12 and Figure 13. By comparison with typical wave modes for mode II delamination of a similar polymer composite system [25], these signals can be clearly classified as shear fracture signals. Thus, it can be concluded that the crack growth during edge delaminating in the laminate tested was due to mode II shear failure, corresponding to the assumption that the edge-delamination failure is caused by high out-of-plane shear $\left(\sigma_{x z}\right)$ (Figure 5). The AE hit rate, cumulative hits, and $\mathrm{AE}$ amplitude histories during a typical edge-delamination tensile test are shown in Figure 14. It can be found that when approaching the edge-delamination onset threshold, the $\mathrm{AE}$ hit rate and the corresponding AE signal amplitudes increased dramatically.

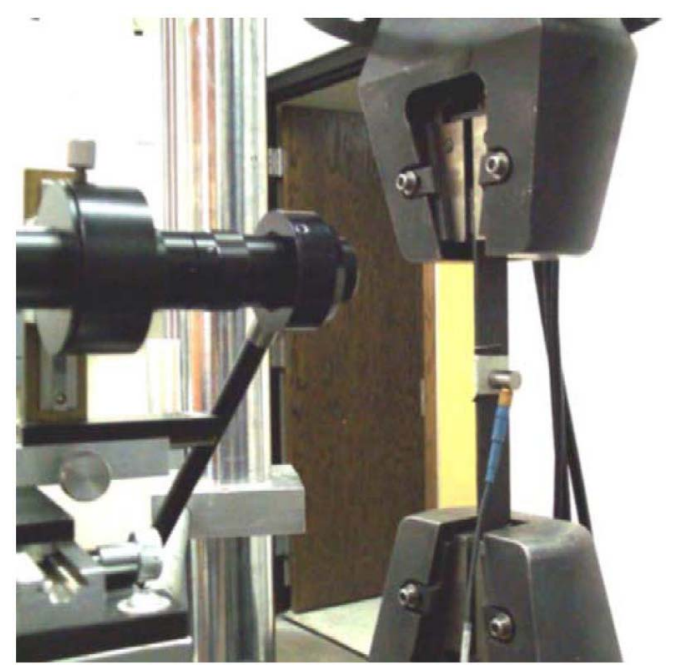

Figure 9. Digital microscopy camera, specimen, AE sensor, and grips.
Measured edge-delamination onset stress and ultimate tensile stress for a group of sixteen samples are tabulated in an ascending serial (Table 2). It can be found that the test results are scattered.

\subsection{Fractographical analysis of edge-delaminated specimens}

In attempt to characterize the microscopic failure mechanisms of the laminate during edge delaminating, SEM fractographical analysis was performed on the failed specimens. During this procedure, all samples used for SEM fractographic analysis were cut from the typical failed $12^{\circ} /-12^{\circ}$ interfaces and then surface-coated with gold. Typical surface scanned by SEM is shown in Figure 15.

It can be observed that the delaminating failure took place along the interfacial layer between two neighboring $12^{\circ} /-12^{\circ}$ laminas of the laminate. The failure

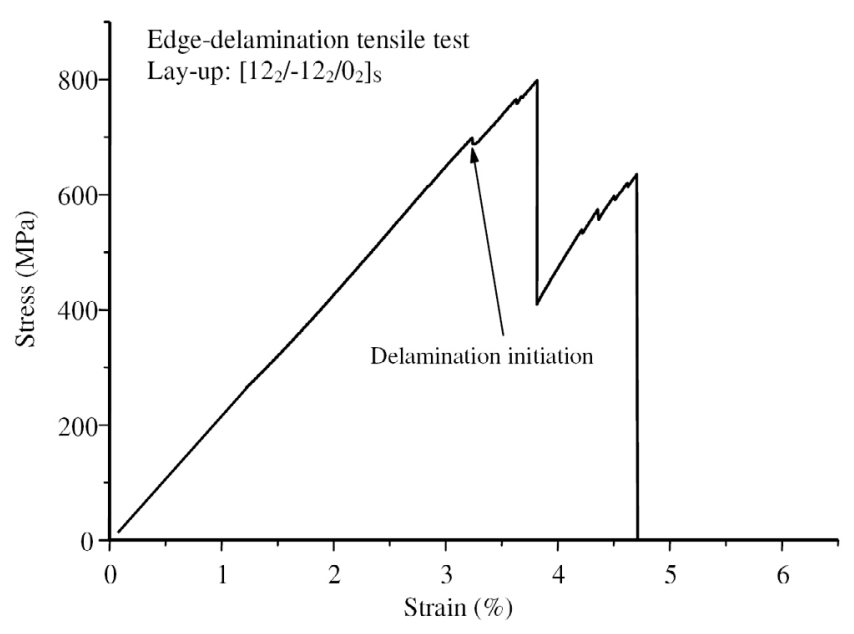

Figure 10. Typical stress-strain curve of regular specimens.

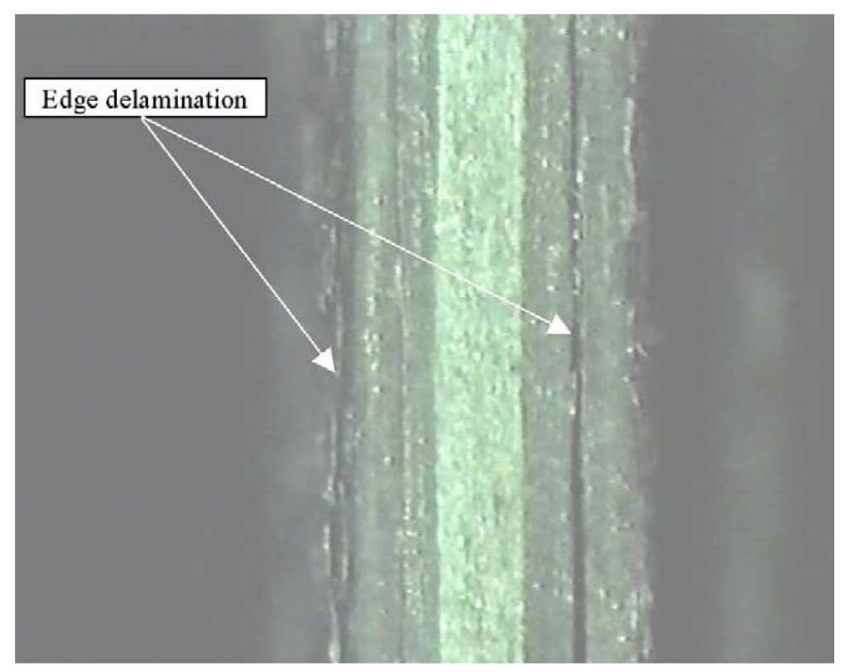

Figure 11. Edge delamination along $12^{\circ} /-12^{\circ}$ interfaces. 

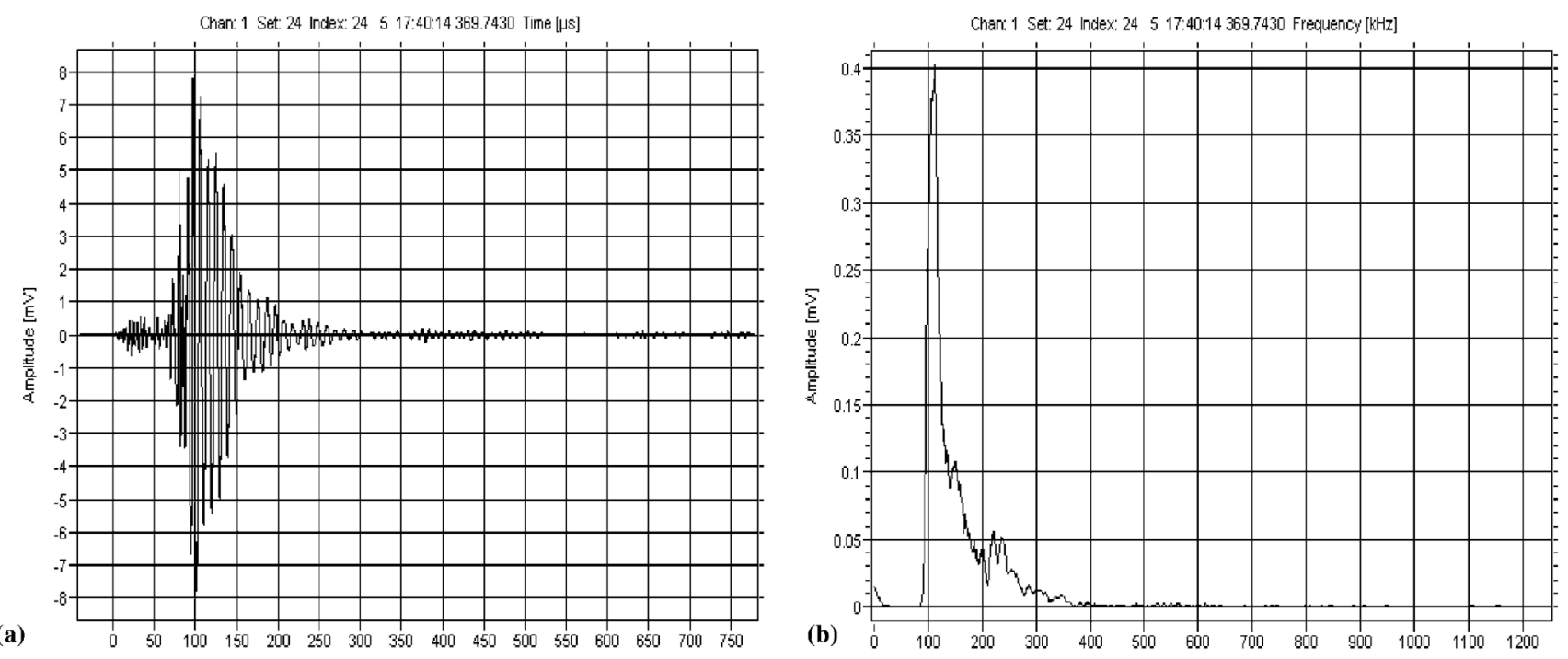

Figure 12. Typical AE signal (1) (a) Transient amplitude-time history; (b) amplitude-frequency spectrum.
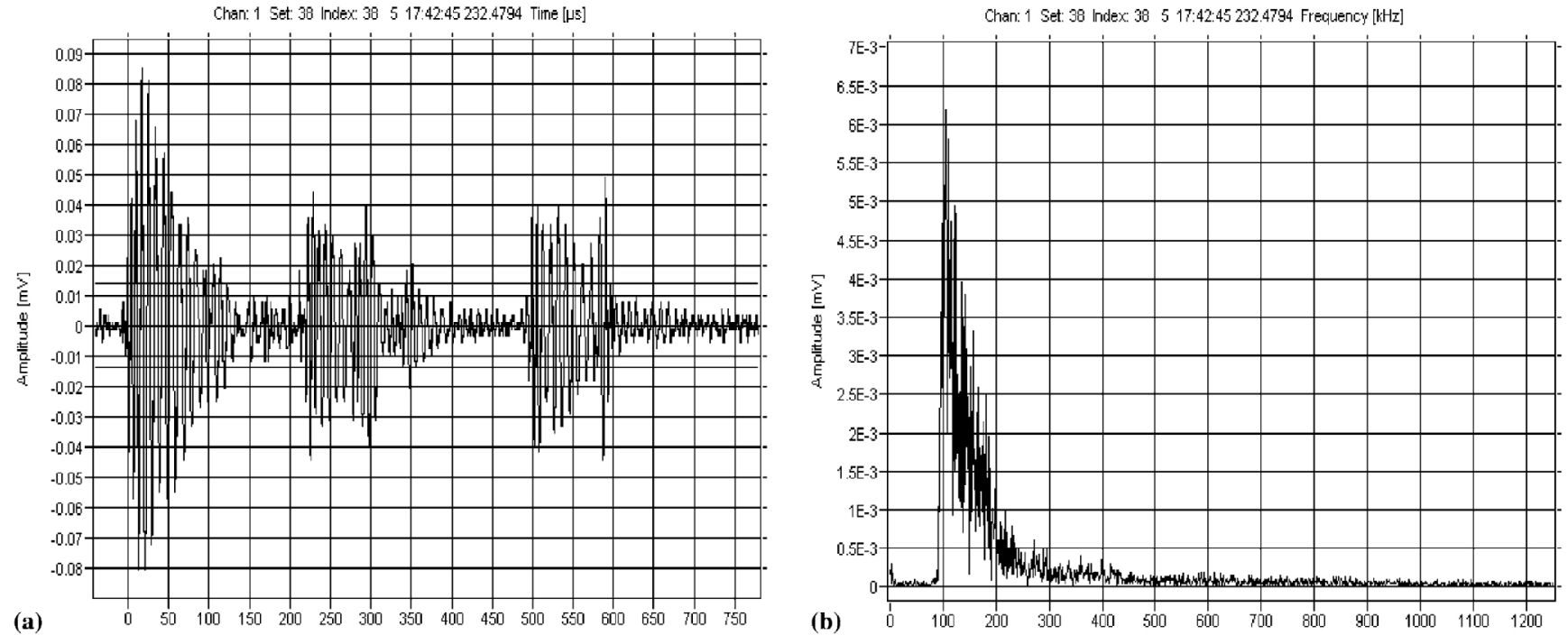

Figure 13. Typical AE signal (2) (a) Transient amplitude-time history; (b) amplitude-frequency spectrum.

features include typical matrix hackle formation and scalloped features between graphite fibers, and fiber/ matrix debonding caused by shear deformation. The very smooth graphite fiber surfaces indicate that the matrix/fiber debonding was triggered by shear loading in mode II failure mode. The complicated matrix hackle profiles and graphite fiber debonding increased the crack surface area, which dissipated much more energy during crack growth. These crack surface features can be used to partly explain why the mode II delamination toughness of laminates is much higher than that of mode I. Fiber breakage was not popular on the crack surfaces, because the main shear stress was parallel to the graphite fibers (lamina plane) as predicted by the aforementioned numerical scheme (Figure 5.), thus graphite fibers were mainly under constrained shear loading. The dominating shear stress led to the fiber/matrix debonding and hackle and scalloped matrix failure features but not fiber breakage due to the high tensile strength of graphite fibers. Thus, the SEM results conform that the edge-delamination between the neighboring $12^{\circ} /-12^{\circ}$ laminas of the laminate is shear-dominated failure.

\section{Probabilistic distributions of edge-delamination on- set stress and ultimate tensile strength}

It has been found from Table 2 that the test data are highly scattered. Thus, hereafter we introduce the prob- 

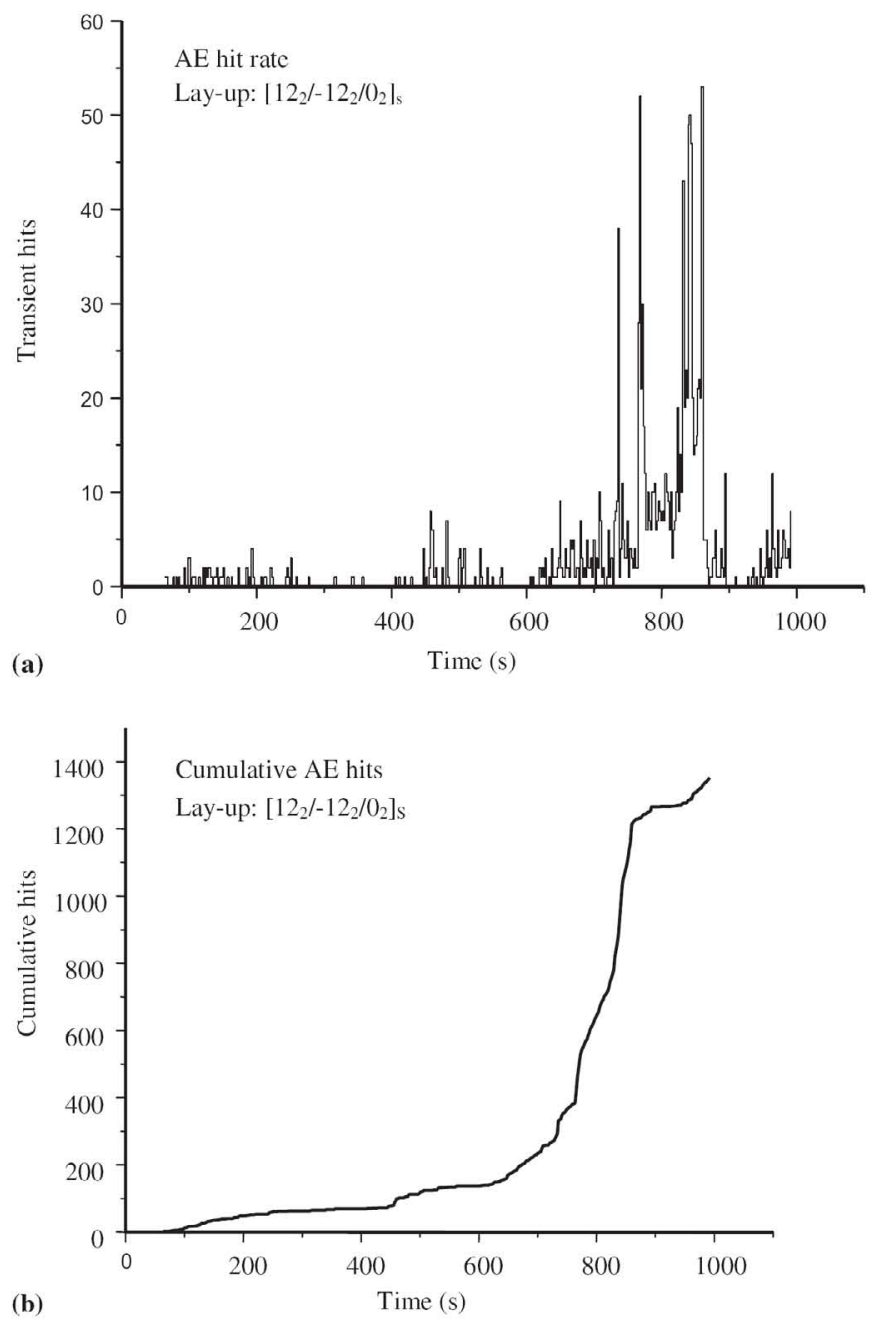

(b)

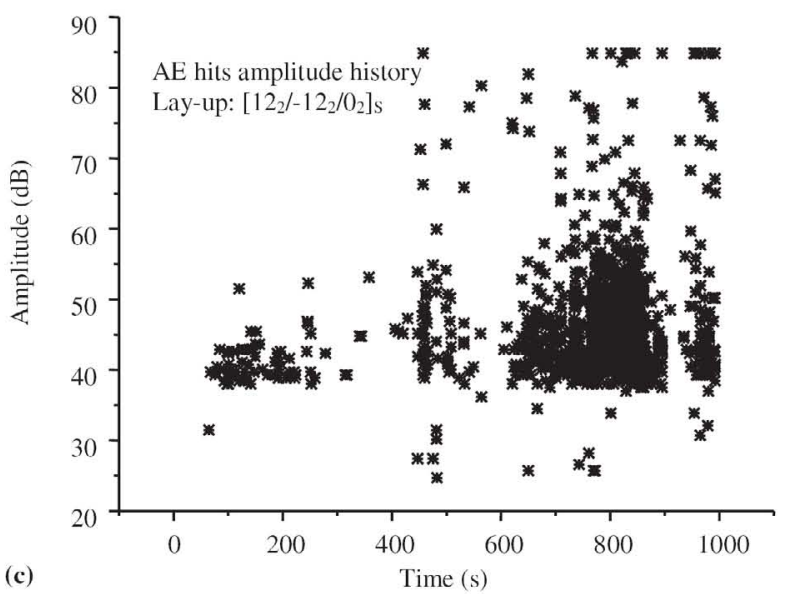

Figure 14. Overall AE history during edge-delamination tensile test (a) Transient AE hits history (b) Cumulative AE hits history (c) AE hits amplitude history.

abilistic models of the edge-delamination onset stress and the ultimate tensile strength of the laminate for data reduction.

In view of reliability theory, the survival probabilities of the residual edge-delamination onset and the resid- ual ultimate tensile failure of the laminate tested are obtained through the median rank formula

$$
f(i)=1-\frac{i-0.3}{n+0.4},
$$


Table 2. Experimental results of edge-delamination onset stress and ultimate tensile strength

\begin{tabular}{lll}
\hline $\begin{array}{l}\text { Serial no. } \\
\text { stress }(\mathrm{MPa})\end{array}$ & Onset stress $(\mathrm{MPa})$ & Ultimate tensile \\
\hline 1 & 652.89 & 676.29 \\
2 & 665.01 & 707.40 \\
3 & 695.57 & 715.47 \\
4 & 718.52 & 731.48 \\
5 & 721.09 & 735.89 \\
6 & 729.13 & 737.38 \\
7 & 733.63 & 794.89 \\
8 & 733.80 & 804.21 \\
9 & 741.93 & 812.66 \\
10 & 758.70 & 815.69 \\
11 & 758.88 & 819.10 \\
12 & 767.74 & 821.78 \\
13 & 777.33 & 836.89 \\
14 & 782.87 & 838.08 \\
15 & 790.68 & 851.31 \\
16 & 834.44 & 855.41 \\
\hline
\end{tabular}

where $i$ is the $i$ th specimen for a sample size of $n$ specimens in an increasing strength sequence. It is assumed that the edge-delamination onset stress and the ultimate tensile strength of the laminate tested obey two two-parameter Weibull distributions, respectively, such that

$$
P(\sigma)=\exp \left[-\left(\frac{\sigma}{\sigma_{0}}\right)^{m}\right]
$$

The mean value is determined as

$$
\bar{\sigma}=\sigma_{0}\left[\Gamma\left(1+\frac{1}{m}\right)\right]
$$

where $m$ and $\sigma_{0}$ are the shape and scale parameters of a two-parameter Weibull distribution, respectively, and $\Gamma()$ is the $\Gamma$-function defined as

$$
\Gamma(s)=\int_{0}^{\infty} x^{s-1} \exp (-x) \mathrm{d} x, \quad(s>0) .
$$

Table 3. Weibull distribution parameters

\begin{tabular}{lll}
\hline Onset stress & $\sigma_{0}$ & $762.51(\mathrm{MPa})$ \\
& $M$ & 17.98 \\
& Mean value & $740.26(\mathrm{MPa})$ \\
& & \\
Ultimate strength & $\sigma_{0}$ & $808.32(\mathrm{MPa})$ \\
& $M$ & 14.94 \\
& Mean value & $780.46(\mathrm{MPa})$ \\
\hline
\end{tabular}

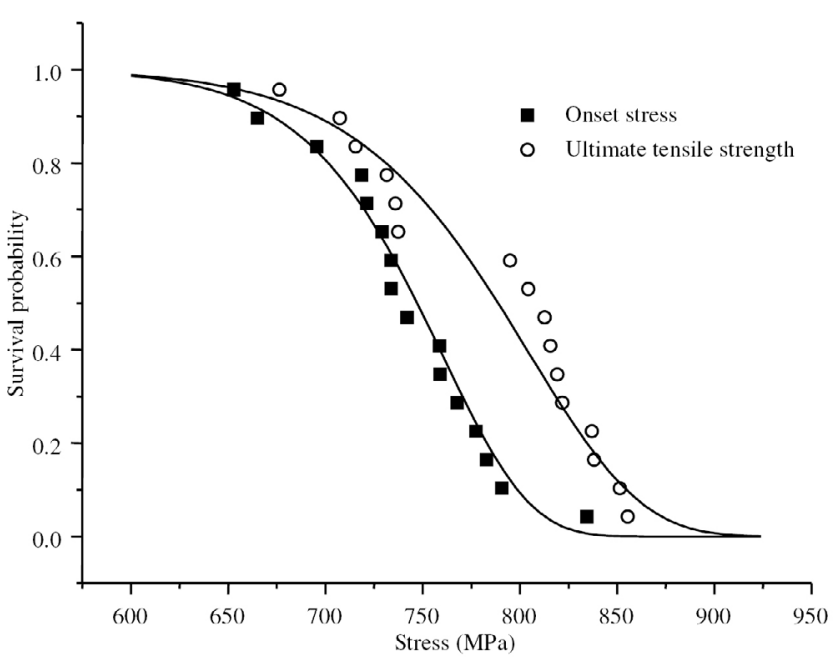

Figure 16. Probability distributions of edge-delamination onset stress and ultimate tensile strength.

The two unknown parameters, $m$ and $\sigma_{0}$ can be determined by means of the maximum-likelihood estimation method as shown in Table 3. In each case, the two-parameter Weibull distribution has an acceptable credibility with $R>0.95$.

Survival probabilities for the measured edge-delamination onset and ultimate tensile failure of the $\left[12_{2} /-\right.$ $\left.12_{2} / 0_{2}\right]_{S}$ laminate tested are plotted with symbols in Figure 16, while those predicted by the two-parameter

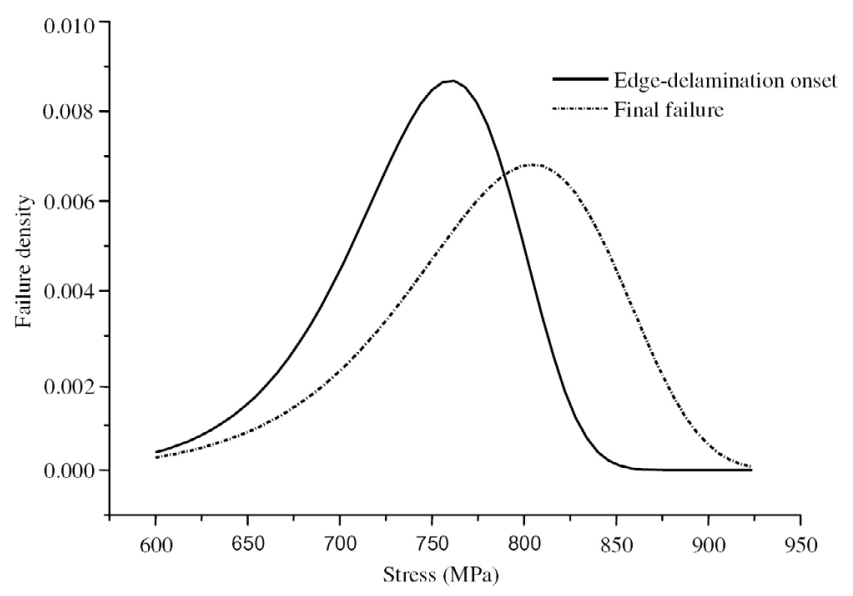

Figure 17. Failure probability density.

Figure 15. SEM fractographic analysis of $12^{\circ} /-12^{\circ}$ interfaces.

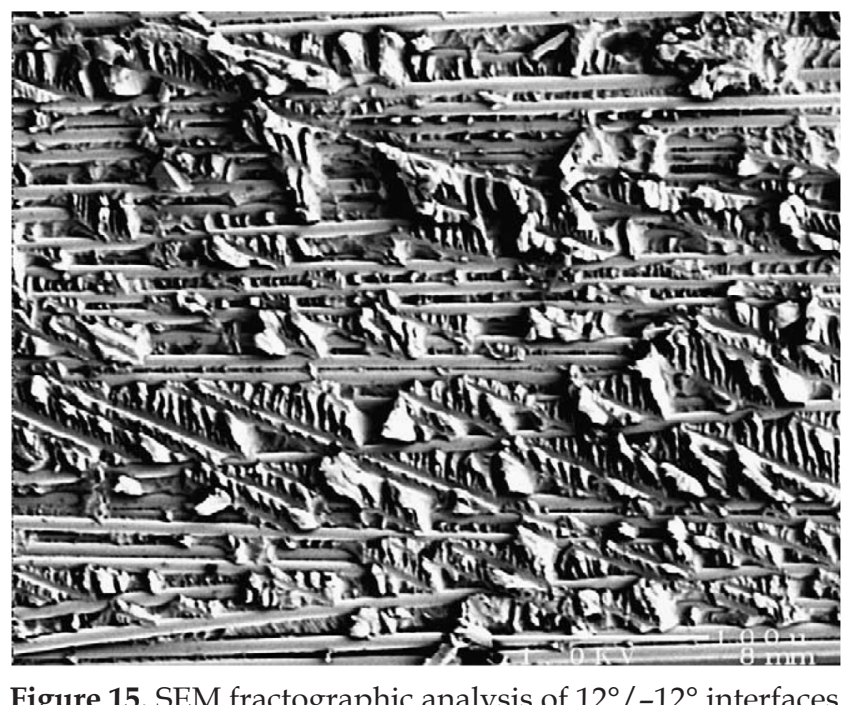


Weibull distribution models are plotted with solid curves. The corresponding failure density distributions are plotted in Figure 17. From Figure 16 and Figure 17, it can be found that the edge-delamination onset stress and the ultimate tensile strength obey the two-parameter Weibull distributions very well, while the onset stress distribution has a relatively higher concentration than the ultimate tensile strength does.

\section{Concluding remarks}

Edge-delamination tensile test has been performed successfully for examining the probabilistic distribution and evaluating the failure mechanisms of a thermosetting graphite-fiber/epoxy laminate made of Toray P7051S20Q-1000 prepregs. Lay-up optimization has been used for laminate design in order to induce maximum out-ofplane stress near free-edges of the composite laminate under constant axial strain. AE equipment and optical microscope were used successfully to capture the edgedelamination initiation, which confirmed the edge-delamination of the laminate predicted numerically. Furthermore, SEM fractographical evaluation of the failed specimens indicated that the main microscopic failure mechanisms of the edge delamination of the laminate tested are mode II shear failure of polymer matrix between two neighboring laminas. Consequently, probabilistic models of two-parameter Weibull distribution have been introduced for data reduction. It has shown that the edge-delamination onset stress and the ultimate tensile strength obey two two-parameter Weibull distributions very well, while the onset stress distribution has a relatively higher concentration than the ultimate tensile strength does. The latter is mainly controlled by the probabilistic distribution of the fiber tensile strength. The methods presented in this research are applicable for the study of reliability of composite laminates, evaluation of interface toughening mechanisms of composite laminates, and the optimization of edge-delamination suppression designs etc.

\section{Acknowledgments}

The support of this work by the US Army Research Office and the US Air Force of Scientific Research Office is gratefully acknowledged. The materials for this study were provided by the Toray Composites America.

\section{References}

1. R. B. Pipes and N. J. Pagano, Interlaminar stresses in composite laminates under uniform axial extension, J. Compos. Mater. 4 (1970), pp. 538-548.

2. N. J. Pagano, On the calculation of interlaminar normal stress in composite laminate, J. Compos. Mater. 8 (1974), pp. 65-81.

3. P. W. Hsu and C. T. Herakovich, Edge effects in angle-ply composite laminates, J. Compos. Mater. 11 (1977), pp. 422-428.
4. A. S. D. Wang and F.W. Crossman, Calculation of edge stresses in multi-layer laminates by sub-structuring, J. Compos. Mater. 12 (1978), pp. 76-83.

5. R. L. Spilker and S. C. Chou, Edge effects in symmetric composite laminates:importance of satisfying the traction-free-edge condition, J. Compos. Mater. 14 (1980), pp. 2-20.

6. A. Altus, A. Rotem and M. Shmueli, Free edge effect in angle ply laminates - a new three dimensional finite difference solution, $J$. Compos. Mater. 14 (1980), pp. 21-30.

7. S. S. Wang and I. Choi, Boundary-layer effects in composite laminates. Part 1: Free-edge stress singularities, ASME J. Appl. Mech. 49 (1982), pp. 541-548.

8. S. S. Wang and I. Choi, Boundary-layer effects in composite laminates. Part 2: Free-edge stress solutions and basic characteristics, ASME J. Appl. Mech. 49 (1982), pp. 549-560.

9. C. Kassapoglou and P. A. Lagace, An efficient method for the calculation of interlaminar stresses in composite materials, ASME J. Appl. Mech. 53 (1986), pp. 744-750.

10. L. Ye, Some characteristics of distributions of free-edge interlaminar stresses in composite laminates, Int. J. Solids Struct. 26 (1990), pp. 331-351.

11. S. K. Datta, A. H. Shah and W. Karunasena, Edge and layering effects in a multilayered composite plate, Comput. Struct. 37 (1990), pp. 151-162.

12. W. L. Yin, Free edge effects in anisotropic laminates under extension, bending and twisting. Part I: A stress-function-based variational approach, ASME J. Appl. Mech. 61 (1994), pp. 410-415.

13. W. L. Yin, Free edge effects in anisotropic laminates under extension, bending and twisting. Part II: Eigenfunction analysis and the results for symmetric laminates, ASME J. Appl. Mech. 61 (1994), pp. 416-421.

14. G. Flanagan, An efficient stress function approximation for the free-edge stresses in laminates, Int. J. Solid Struct. 31 (1994), pp. 941-952.

15. H. T. Y. Yang and C. C. He, Three-dimensional finite element analysis of free edge stresses and delamination of composite laminates, J. Compos. Mater. 28 (1994), pp. 1394-1412.

16. G. Davi and A. Milazzo, Boundary element solution for free edge stresses in composite laminates, ASME J. Appl. Mech. 64 (1997), pp. 877-884.

17. P. Gaudenzi, A. Mannini and R. Carbonaro, Multi-layer higher-order finite element for the analysis of free-edge stresses in composite laminates, Int. J. Numer. Methods Eng. 41 (1998), pp. 851-873.

18. M. Cho and H. S. Kim, Iterative free-edge stress analysis of composite laminates under extension, bending, twisting and thermal loadings, Int. J. Solids Struct. 37 (2000) (3), pp. 435-459.

19. A. Makeev and E. A. Armanios, An iterative method for solving elasticity problems for composite laminates, ASME J. Appl. Mech. 67 (2000), pp. 96-104.

20. A. P. Suvorov and G. J. Dvorak, Optimized fiber pre-stress for reduction of free edge stresses in composite laminates, Int. J. Solid Struct. 38 (2001), pp. 6751-6786.

21. M. Tahani and A. Nosier, Free edge stress analysis of general crossply composite laminates under extension and thermal loading, Compos. Struct. 60 (2003), pp. 91-103.

22. R. M. Jones, Mechanics of composite materials (2nd ed.), Taylor and Francis (1999).

23. X.-F. Wu, Fracture of advanced polymer composites with nanofiber reinforced interfaces. Ph.D. dissertation. University of NebraskaLincoln, Nebraska, USA, August 2003.

24. Y. A. Dzenis and J. Qian, Analysis of microdamage evolution histories in composites, Int. J. Solid Struct. 38 (2001), pp. 1831-1854.

25. Y. A. Dzenis and I. Saunders, On the possibility of discrimination of mixed-mode fatigue fracture mechanisms in adhesive composite joints by advanced acoustic emission analysis, Int. J. Fract. 117 (2002), pp. L23-L28. 